\title{
Early State Formation: A Complete Rejection of the Circumscription Theory
}

\section{Terry Stocker}

Independent Scholar

\section{Jianyi Xiao}

Xianyang Normal University

\begin{abstract}
We evaluated Carneiro's 'environmental circumscription' theory and completely rejected it. It was an insidious ethnocentric prima facie construct. Attempting to develop a viable alternative to early state formation, we focused on food procurement, production and storage. Obviously, large population aggregates (characterizing a state by archaeologists) was only possible because they were in areas of unique abundant wild/renewable food resources, supplemented with agriculture in varying degrees of development. All earliest states followed a pattern of being located near a river mouth entering a sea or ocean. Thus, we propose that such areas produced large amounts of aquatic fauna (mainly fish) and sometimes flora, and these renewable resources helped support sizeable human populations. We label our theory: Unique Resource Constellation Theory (URCT).
\end{abstract}

\section{INTRODUCTION}

Jonathan Haas wrote in 1982: 'One of the favorite pastimes of social scientists over the course of the past century has been to theorize about the evolution of the world's great civilizations.' Nearly 30 years on, the situation has not simplified. We intend to streamline the issue by first negating circumscription theory, and second by acknowledging that the population aggregates of any early state were only in areas of unique abundant wild/renewable food resources, supplemented with agriculture in varying degrees of development.

Zinkina, Korotayev, and Andreev inform us:

By now it is hardly possible to find a paper on state (and chief-

dom) formation with a higher citation index than the one of

Social Evolution \& History, Vol. 18 No. 2, September 2019 166-190

(C) 2019 'Uchitel' Publishing House

DOI: $10.30884 / \mathrm{seh} / 2019.02 .09$ 
'A Theory of the Origins of the State' by Robert L. Carneiro (1970). It is hardly possible to find a student of this subject who has never experienced the charm irradiated by this simple and elegant model which promises to explain so much (Zinkina, Korotayev, and Andreev 2016: 187).

'Environmental circumscription' supposedly occurred when an area of productive agricultural land was surrounded by less productive land thus inhibiting out-migration. Therefore, the growing population in the productive area would wage war on one another (over resources) and the losers would submit to the victors, consequently creating the earliest state formation(s), with a highly stratified society, led by a ruling elite.

\section{CONQUEST WARFARE}

The initial premise of Carneiro's 'Environmental circumscription' is that states arise because some ecological barrier circumscribes a population, prohibiting that population from escaping, and we attend to this below. The second premise is that a state level of social organization comes about in the circumscribed area because warfare breaks out over critical resources, and the winners conquer the losers, thus setting up a stratified elite who rules over a non-elite. Carneiro's article (2012a) is devoted to a discussion of warfare, in which he sees warfare as a near cultural universal (also see Carneiro 1998, 2016).

Zinkina, Korotayev, and Andreev critique the warfare variable, writing specifically:

In fact, the main flaw of Carneiro's theory of state formation is that it implicitly assumes that every community dreams to conquer its neighboring communities. Only with this assumption does Carneiro's theory make sense. All the available data seem to show that the conquest-warfare culture is a rather late phenomenon which does not appear to be found in independent communities (Zinkina, Korotayev, and Andreev 2016)).

After a thorough analysis of data they (Ibid.: 192) present a most salient conclusion (Ibid.: 192): 'The general impression is that conquest warfare should be regarded not as a cause of chiefdom and state formation, but rather as one of its results.' An ancillary aspect of this is Schaedel and Robinson's (2004: 262-263) idea that the Olmec were probably created through voluntary participation in a shared belief system.

Indeed, as Zinkina, Korotayev and Andreev (2016: 195) point out, Carneiro $(1998,2012$ a) himself reorganized his thoughts to suggest a model explaining how simple chiefdoms could appear in the absence of conquest warfare. However, in his monograph The Muse of History and the Science of Culture, Carneiro (2000: 184) renders his new thinking with these words: 'As fighting in circumscribed areas intensified, autonomous villages formed alliances with each other as they thought to protect themselves from any attacks.' 
Herein lies the main issue we will undertake: 'circumscribed areas.' These exist only in Carneiro's mind. We agree with Zinkina, Korotayev and Andreev completely, except for their use of 'the main flaw' of Carneiro's theory. For us, 'the main flaw' is the initial premise, lending its name to the theory: 'Environmental circumscription.'

\section{ENVIRONMENTAL CIRCUMSCRIPTION}

For us, it is more than disconcerting that no one ever challenged the total lack of data in Carneiro's 1970 article. (We might have done so earlier, but we never read the article until 2016.) For example, he proposed that Mexico's earliest state is in the Valley of Mexico, but he never provides a site or any references, and he continues the same thing in his later article (Carneiro 2012a). The same applies for his generalizing of China's earliest state, supposedly in the Hwang Valley, without any designated site or references. Moreover, in both cases (Mexico and China), the earliest states are not in the regions nominated by Carneiro. If we as students had submitted class papers on state formation with no sites or citations for the areas we proposed, our professors surely would have given us failing grades.

All of Carneiro's articles expanding on his 1970 article, published in Science, follow a formula of overgeneralizations with very little data. We cite a majority of those articles. The main intent of our article is to dispense with 'circumscription theory', which has influenced too many, including an entire issue of American Behavioral Scientist, in which Carneiro (1988) makes a few amendments to his 1970 article, but the critical erroneous concept remains: 'circumscription theory.' Likewise, in The Early States: Its Alternatives and Analogues (2004) many good ideas were presented, but no one challenged 'circumscription theory', while Carneiro (2004) again totally referenced his 1970 article. Our main attention to his 2012a article is in our conclusions below.

\section{ETHNOCENTRISM}

The basis for Carneiro's beliefs about 'environmental circumscription' smacks of deceptive ethnocentrism, which again has gone unchallenged until now. So, before discussing cases of early state formation, we attend to a major constraint of Carneiro's thinking.

Carneiro used the Basin of Mexico as his example of environmental circumscription for the early state in Mexico, and according to him 'high' mountains surround the Basin of Mexico, and this would have impeded out-migration. This is a very ethnocentric projection on a population that walked everywhere it went, and for whom mountains were not a hindrance. Apparently Carneiro did not consider the fact that the same mountains did not keep people from migrating in.

Undeniably, humans populated planet Earth by walking 'everywhere', including over mountains and across deserts. At one point, Car- 
neiro concludes that Egypt had its great civilization because people were hemmed in and could 'never run' into the desert.

However, the founders of Israel are documented to have not only 'run' into the desert but also crossed it. In this case, the desert was not the limiting factor for the Hebrews, rather the social law that prohibited their out-migration (escape). (Perhaps, we can call this cognitive circumscription?) This example of social/cognitive control exists to some extent in all states, including early ones. For example, we know the Shogun banned travel outside coastal waters, prohibiting Japanese fishermen's boats to be equipped for long voyages; and thus sometimes when blown out to sea, they drifted to America (Plummer 1984). In recent times (in the lives of both authors), the Chinese and Korean populaces were prohibited from traveling abroad. Americans were prohibited from traveling to Cuba.

More specifically, we maintain that slavery worldwide was a critical variable in human social regulation and a probable critical variable in early state materializations, because the institution of slavery sometimes supplied labor for monumental architecture. And of course, slavery obviously limited human movement.

Historically, the mountains surrounding the Basin of Mexico, which are not that high, did not keep the Aztecs from migrating into the basin or from marching armies out to conquer more fertile areas as far away as Guatemala (cf. Stocker 1987). Nor did those mountains keep conquered communities from bringing their tribute to the Aztec capital of Tenochtitlan. Finally, in 1487, the Aztecs crossed those same mountains, marching to the distant land of Guerrero, almost annihilating two towns there, and then repopulating them with people from their own burgeoning capital (Stocker and Kylar 1984; Silverstein 2001). Everyone was walking over the mountains!

As for the specific mountains surrounding the Basin of Mexico, every year millions of Mexican pilgrims walk over them to arrive at the Basilica of the Virgin of Guadalupe, the most visited site in the Catholic realm. Stocker (a non-Christian), with no great exertion, has made that three-day (annual) pilgrimage from Tula, Hidalgo over the mountains of the Basin of Mexico, which Carneiro proposed would hem in people. Worldwide, mountains hemmed in no one; nor kept people out.

\section{ENVIRONMENTAL CIRCUMSCRIPTION}

In a brief introduction, Carneiro (1970) notes that, we lived in bands and tribes for the first 2 million years of human existence; but in certain locations, certain populations aggregated and states came into being about 4000 BC. Voluntaristic Theories we are informed fail to explain the rise of the state. Coercive Theories supply a necessary condition for explaining the rise of the state, because no group willingly surrenders its autonomy to work for another group. 
However, this factor is not sufficient to explain early states. Carneiro never considers why the populations of early states aggregated where they did.

With Environmental Circumscription, Carneiro provides his main argument by comparing coastal Peru to the Amazon. The former had early states; the latter did not. Under the heading of Political Evolution he generalizes his Peruvian case to other areas, including Mexico, without one reference for the latter! Carneiro uses the Amazon River basin to exemplify Resource Concentration, because human populations concentrated along the river to exploit abundant riverine resources. Providing this specific information has nothing to do with state formation.

Repeating, Carneiro never considers why the populations of early states gathered where they did. We will propose that the populations of early states gathered where they did because of abundant food resources. The first order of business of archaeologists is to determine how any population survived where it did. Thus, no circumscribed barriers kept people from migrating to those resources (or move away from them).

When he could find no physical impediment for human movement, he informs us that often groups were impeded from moving because other people hem them in. This he terms: Social Circumscription. He presents us with information on tribal Yanomamö of Brazil's Amazon basin, whose contemporary circumscription results from the capitalist expansion of commercial ranching, hardly relevant to the earliest states. Yet, we are informed:

With these auxiliary hypotheses [his use of plural] incorporated into it, the circumscription theory is now better able to confront the entire range of test cases that can be brought before it. For example, it can now account for the rise of the state in the Hwang Valley of northern China... (Carneiro 1970: 737)

As with his use of Mexico, he provides not one citation for his conjured characterization of China.

Carneiro informs us that the entire Amazon basin has unlimited agricultural land, yet due to a lack of mountains or deserts to hem in people, there were no large aggregations of people, thus no state formation. We caution against using the idea of unlimited agricultural land, because at the time of most early states, agriculture was incipient. And furthermore, to this day, with modern equipment, most of the Amazon basin cannot be farmed (Hecht and Cockburn 2011).

He then compares the Amazon basin to coastal Peru, but we are warned: 'The reconstruction of these events that I present is admittedly inferential, but I think it is consistent with the archaeological evidence' (Carneiro 1970: 735). Some five decades later his admittedly inferential surmising seems not to be the case.

In Peru, he sees small, dispersed, and autonomous farming communities confined to 78 short and narrow river valleys running from the Andes 
to the Pacific Ocean. 'Each of these valleys, moreover, was backed by the mountains, fronted by the sea, and flanked on either side by desert as dry as any in the world. Nowhere else, perhaps, can one find agricultural valleys more sharply circumscribed than these' (Ibid.).

As with his oversimplification of the Basin of Mexico, Carneiro never informed us of how people populated the 78 narrow Peruvian valleys. They obviously 'overcame' the same impediments he presents for their inability to 'escape.' Furthermore, he never demonstrates any agriculture for early dates. Finally, he never mentions which of the 78 river valleys might have developed an early state. As with the Basin of Mexico and the Hwang Basin, it is all of Peru; he provides no sites and no references.

\section{UNIQUE CONSTELLATION THEORY}

As for state classification, we follow Service's (1975) definition: highly stratified social organization reflected in monumental architecture and art. The population figure of 100,000 is obviously arbitrary and certainly not concentrated at one site. Indeed population estimates for any prehistoric sites are debatable. For a more detailed understanding of population dynamics of the early state we recommend Grinin 2004.

For the purpose at hand, we focus on those areas that archaeologists have known about from the initial stages of our profession, and all are mentioned by Carneiro in the countries of Iraq, Pakistan, Egypt, China, Mexico, and Peru (see also Haas 1982). We discuss specific sites and their river valleys below; but for the present we want to emphasize that archaeologists interested in early states accept the fact that something unique occurred in at least six specific regions of the world, which permitted a large population to be fed. This is the fundamental issue: How were the people of any early state fed?

Sanderson (1990: 143) ends his characterization of Carneiro like this, 'He also adds the notion of resource concentration as an occasional factor in political evolution. An area that is particularly abundant in plant and animal resources tends to attract many people to it and permits substantial population growth.'

Again, Carneiro's segment (1970: 736-737) on Resource Concentration is totally vague, him mentioning that the coast of Peru had a concentration of sea resources. He continues his vague characterization in his 2012a article. As we will discuss below, some sections of Peru's coast had heavy concentrations of sea resources, not all of it.

Carneiro (1970: 736) informs us, 'In the 1500s, the native population living on the banks of the Amazon was relatively dense...' This description of the Amazon River is disconcerting seeing this is one area of Carneiro's expertize. Denevan (2001) notes that there were dense populations along some resource-rich sections of rivers in the Amazon basin and sparse settlements between rivers (emphasis ours). It is our understanding 
that 'most' settlements are not on the banks of the Amazon River, which floods annually, but away from the banks on nearby knolls (see also Clement et al. 2015). Actually, characterization of human settlement in the Amazon River basin is complex, especially when viewed with new data over a long period of time (see Heckenberger et al. 2003).

However, we propose that resource concentration is not an occasional factor, but a constant of all early states, and in fact is the most critical variable. Indeed, we present data that indicate that the earliest states worldwide were not in circumscribed areas; furthermore, they all appear to share an apparent reliance on abundant wild animal and plant resources, with all early states being located near a river mouth entering either a sea or ocean. This is a working hypothesis that future archaeologists can evaluate and test for. In the future of this debate, archaeologists must determine what food procurement and production was available to support any large population, as well as how that food was stored.

Later, Carneiro (1987) began to reconsider resource concentration, and he did amend his later thinking:

Already in 1970, I had introduced resource concentration as one of the auxiliary factors capable of inciting the kind of warfare that resulted in territorial conquests. However at the time I did not assign it the importance I now see it deserves. Not being fully aware of this importance, I failed to point out that most of the circumscribed environments where the earliest archaic state arose were also areas of resource concentration (italics in the original) (Carneiro 2012a: 21-22).

Certainly, this in part lends support to our final conclusion, except for the 'circumscribed environments.' And again, per usual, Carneiro provides only vague generalizations (of resource concentration): '...migration of birds to the reed banks of the Fayum [Egypt] in winter is still an impressive event, but in antiquity the wealth of pond fowl and fish... was even more prodigious...' (Aldred 1987: 50)

Furthermore, we are unsure of what he means by '...inciting the kind of warfare that resulted in territorial conquests.' Does this mean that the people in areas of resource concentration had so much food that they wanted to (needed to) conquer others?

We will expand on resource concentration, but we are adamant that there are no circumscribed environments. We label our theory: Unique Resource Constellation Theory (URCT), but a more accurate description might be: 'highly concentrated riverine resources theory of early states.' As a baseline in state studies, we have to assume that early peoples spreading around the globe would gravitate to areas where certain wild subsistence resources (plant or animal) were abundant. For a time, life might have been idyllic with a low population and abundant food. However, as these areas experienced population growth, and further attracted migrant populations, 
problems of access to resources needed to be resolved, and an elite emerged (may have already existed) as the problem solvers, and early states arose.

While the earliest states only occurred in specific locations that provided a unique constellation of plant and animal resources to support large human populations, we must assume that agriculture to some degree was the critical variable allowing state formation. Thus, the U.S. Northwest, with its amazing salmon resources never supported a state-level of social organization.

In the areas of early states, both agricultural and wild resources would have been processed and stored; otherwise the populations would have been mobile, hunters and gathers, and obviously this food storage began at the village level, and it only was possible in an area where there was an abundance of food resources. Surely, after a time, those stored resources would have been targets of raid for those people having limited food resources; and thus, warfare probably becomes a critical variable, at some level, of state dissolution.

Our data presentation needs to be prefaced by what limits all archaeologists, not just those studying state formation: What did any people eat? Currently, with isotope analysis we can better understand certain parameters of prehistoric diet. More specifically, the multi-proxy analysis of plant use at Formative Period Los Naranjos, Honduras by Morell-Hart, Joyce and Henderson (2014) helps us realize that maize was not as central as expected to the early inhabitants of much of prehistoric Mesoamerica. Still, we need more research concentrating on the very foundation of the state: food procurement, production, processing, storage and consumption.

Carneiro questions how are we to determine environmental conditions ... in... areas such as the Nile, Tigris-Euphrates, and Indus valleys in the Old World and the Valley of Mexico...? They ... have one thing in common: 'they are all areas of circumscribed agricultural land' (Carneiro 1970: 734, emphasis in the original). Again, he supplies not a single citation for specifics of any of these four regions. We shall offer some. Although we will neither detail the obvious link of the Indus Civilization and the Indus River, nor the fact that the Mesopotamian early states were on the Tigris and Euphrates Rivers.

\section{PERU}

A few years before Carneiro's article, a debate began about the amount of agriculture that might have been practiced by Peru's Preceramic population, with little evidence for major agricultural practices (see Lanning 1967). It is now accepted that Peru's early state formation was based mainly on maritime resources, beginning with Stocker and Jackson's (1982) presentation of data in 'Peru's Preceramic Menu.'

For years anchovies' remains in Peru's Preceramic sites caused a conundrum. Because anchovies are a deep-water fish, one idea was that Pe- 
ru's Preceramic population had boats and nets, which could not be demonstrated archaeologically.

In 1979 Stocker socializing with the locals in Peru was advised of anchovy beachings, and he was fortunate to witness one. A school of mackerel surrounded a school of anchovies and drove them to shore, a beach, where the anchovies beached themselves by the hundreds of thousands. The locals were not interested in the anchovies, rather they baited metal hooks with an anchovy, casting them back in the water and almost immediately catching a mackerel. Within an hour, one person could catch 20-40 large mackerels. The locals said this phenomenon transpired two to three times a year.

We emphasize that this is a very rare phenomenon. Indeed, anchovy beaching can only take place where there is a beach. If the incident had taken place five kilometers up or down the coast, the anchovies would have encountered cliffs.

Again, Carneiro (1970: 737) talked of the whole Peruvian coast, without specifying one place or specific food type. 'The notion of resource concentration also helps to explain the surprising degree of political development apparently attained by people of the Peruvian coast...' (Ibid.). This type of generalizing has no place in a scientific endeavor of trying to understand the rise of the state.

The largest of Peru's Preceramic centers is El Paraíso (58 hectares) located on the Chillón River delta, 2 kilometers from the Pacific Ocean. For decades El Paraíso's largest building (of eleven, Quilter 1985) was labeled a temple; however, Stocker and Jackson (1982) interpreted it to be, at least in part, a granary.

Dried anchovy can be stored for centuries. Stocker assumes that the amount of anchovies he saw the next day after the beaching at San Bartolo could have filled the El Paraíso granary, but without photos and at least some limited calculations, we are left to wait for any possible data. (Such was Stocker's low level of awareness at the time, unfortunately.)

Quilter and Stocker (1983) built upon Stocker and Jackson's findings in 'Further Considerations of the Maritime Foundations of Andean Civilization.' In that article, Stocker wanted to argue for whales (via beachings) as a major component of the Peruvian diet; but without the bones, readers are cautioned against any speculations. Whales' bones are found in Peru's Perceramic sites, including the struts for a circular house at Chilca, dating to 3500 B.C. (Bruhns 1994: 71). The question will remain about whale beachings, because people had no reason to carry whalebone to inland sites.

A year later, in 1984, Smith and Kinahan published 'The Invisible Whale,' a major contribution to archaeology, by using historical and anthropological documents, explaining how groups of southern Africa butchered stranded whales, burying blubber in the sand for storage or drying some of the meat. Little survives for archaeologists to find. 
It will be up to young scholars to document worldwide whale beachings and their significance for human populations. (The blue whale (skeleton) placed on display in the British Museum in 2017 had beached in Ireland in the $1800 \mathrm{~s}$, and that was after whale populations had been greatly reduced, leaving us to wonder how many blue whales might have ever beached in Ireland and elsewhere in the world.) As of 1984, Food and Agriculture of the U.N. estimated that only four percent of the original blue whale population survives from pre-whaling numbers (Smith and Kinahan 1984: 94).

Later, Quilter et al. (1991) documented that fish was El Paraíso's main food animal, but that certain flora added to the diet: cultivated plants (squash, beans, jicama), fruits (guava, lucuma, pacae), with possible utilization of wild plants (sedges and cattails).

While we applaud Quilter's work to identify food resources, we find limitations in not realizing that people must store their food somewhere (otherwise people would just be hunters and gatherers). Surely some of the rooms in El Paraíso's large buildings were used for food storage. Quilter (1985: 285) mentions a layer of black soil in some rooms, and we offer the idea that this might have been disintegrated anchovy meal. In the future, chemical tests will be essential.

\section{MEXICO}

Carneiro's 1970 designation of the Valley of Mexico as the location of a pristine state is sophomoric, to say the least. The Valley of Mexico is a very large place. To talk about state formation we need to reference a main site. He provides no citations of any kind to characterize the prehistory of the Valley of Mexico.

It is now generally accepted that Mexico's earliest state was not in the Basin of Mexico, rather probably on the gulf coast area centered at the Olmec site of San Lorenzo, which has no physical circumscription (see Clark and Pye 2000: 245). Pool notes that San Lorenzo was built on some 1700 acres, modified by moving 2,000,000 cubic meters of earth, and populated by up to 13,000 people (Pool 2007). Indeed, it was Pool's 2006 paper that caused Carneiro (2012a: 12) to write, '...we are forced to conclude that tight geographic constrictions, while greatly aiding state formation is not absolutely essential to it.' We return to this point in the end.

San Lorenzo is located on the Coatzacoalcos River, and this verdant environment produced a unique constellation of wild plants and animals that enabled a large population to congregate. Arnold (2009) documents that floodplain resources (not maize agriculture) were the subsistence base of the Early Formative Olmec. Killion (2013), in a most stimulating article, refers to the early Olmec as hunter-fisher-gardeners. Stocker and Ortega (N.d.) have proposed that this population relied heavily on aquatic re- 
sources, especially crocodilians. A question for future archaeologist to entertain and hopefully solve: Did the Olmec farm crocodilians?

Anthropologists are becoming more aware that wild plants heavily supplement the rural Mexican diet (cf. Stocker 1986, 2015), and this was important in the past (Casas et al. 1987; Bye 2000). Indeed, Casas et al. (2007) and Caballero et al. (1998) speculate that around 600-700 species are currently managed in forms that fall in the middle ground between wild and cultivated.

Killion states:

A simple distinction between food procurement and food production, however, ignores intermediate states, masking real-world variation among these categories and the range of behaviors signified by each ... The middle ground of mixed subsistence, based on a combination of cultivated crops and collected wild resources, is an important context for understanding relationships among population, subsistence intensification, and social complexity in the past and a critical modality of human organization and economic change as landscapes of early agricultural production became dominant around the globe...( Killion 2013: 569)

Fortunately, some anthropologists are now calculating the percentage of wild plants consumed by certain populations (see Lira et al. 2016). Stocker (N.d.) discovered that possibly up to 50 per cent of San Ildefonso's (Hidalgo, Mexico) recent past diet consisted of wild plants.

Working in Ixhuapan, Veracruz (near San Lorenzo, Mexico's presumed first state), Vázquez-García et al. (2004: 448) documented the frequency of consumption of 44 cultivated and 84 uncultivated foods. Furthermore, they (Ibid.: 449) found that women identified 19 uncultivated plant foods, a fourth of which are quelites: white quelite (Amaranthus hybridus C.), purple quelite (Solanum nigrecens), chipile (Crotalaria langirostrata), and papalo quelite (Porophyllum macrocephalum).

Demonstrating the variety of wild foods and their percentage to the diet will be a challenge for future archaeologists. And we do qualify that San Lorenzo is not 'near' the mouth of the Coatzacoalcos, but it is as close as a large site could be without enduring the major annual flooding in this jungle area. The river basin-area surely comprised part of the San Lorenzo's catchment area.

Also, tropical fruit trees could have provided abundant food, and if managed as orchards would have greatly contributed to a population like San Lorenz (see Morton and Dowling 2013). Two fruits native to that area, papaya and sapote, are high producers (cf. Bost 2009). The sapote is credited with sustaining Cortez and his army in their historic march from Mexico City to Honduras (Morton and Dowling 2013: 400).

In fact, near Mexico's first state, Santley (2007: 27) writes (of Early Formative subsistence in the highlands of Veracruz) that three tree crops 
were avocado (Persea americana), coyol palm (Acrocomia mexicana) and sapote (Pouteria sapote). He notes that these trees, '...likely were the main plants cultivated in the gardens of households or in the managed forest near the site.'

We also believe in the possibility of managed forests or orchards. Now, future archaeologists will have to determine how much these tree crops contributed to any diet.

\section{CHINA}

Carneiro, without any reference to a specific site, used the Hwang Valley in Northern China to introduce his conjured idea of 'social circumscription', because the Hwang Valley was an obvious exception to his physical circumscription. The Hwang Valley is a very large place, almost the size of all of Mesoamerica.

More to the point, Carneiro never defines social circumscription. Are we to believe that a state level of social organization existed in the Hwang Valley and an additional human 'layer' was so densely packed around it that the central population could not move out if wanted to? In brief: never happened (anywhere in the world) (see also Carneiro 1972).

Sanderson writes,

Carneiro has also added a few wrinkles to his basic argument to give it a broader explanatory scope. He notes that circumscription may sometimes take the form of social circumscription. This occurs when the barriers to movement involve the presence of other societies rather than aspects of the physical environment (Sanderson 1990: 143).

We certainly, agree with the term 'wrinkle.' Furthermore, we find it difficult to understand Carneiro's penchant for seeing the landscape as a place of never-ending warfare, why the supposed state level of social organization of the Hwang Valley did not simply fight its way out.

Most importantly, China's earliest state is centered in the Yangtze River Delta at the 290-hectare city of Liangzhu, circumscribed by clay walls (Liu and Ling 2018; Underhill 2013: 574; Ying 2007). Those walls were apparently for defensive purposes, as people came together to secure themselves from others.

Liangzhu had a granary that could hold up to $15,000 \mathrm{~kg}$ of rice grain. Thus, it would appear that this early state had more than just incipient agriculture. Also, over 300 Liangzhu communities have been found, the majority located near rivers (cf. Lin et al. 1973). This follows the Olmec (Gulf Coast of Mexico) pattern of apparent reliance on aquatic resources. Furthermore, there is solid evidence that Liangzhu practiced aquaculture (Chi and Hung 2008).

In their aquaculture, did the Liangzhu people monitor the alligator population? We know they existed (and are now endangered) in the Liang- 
zhu region of China. In fact, the Chinese alligator is also called the Yangtze alligator. Alligator bones have been excavated at Liangzhu sites. The main point here is that reptiles have a very high reproduction rate and if monitored could supply an on-going, large amount of meat. Everywhere in the world alligators or crocodiles are found, they are eaten (see Stocker et al. 1980). The basic problem is that we need greater ethnographic documentation on this worldwide.

Presumably, Liangzhu people also ate seaweed. The consumption of seaweed worldwide is one of the most understudied aspects of human diet throughout time; and seaweed can be easily gathered near certain rocky shores. In Korea and Japan, seaweed is a staple, not a supplement (cf. Stocker 2002), but historical data only goes back to the fifth century in China (see Tseng 1981). Furthermore, in South America, nine species of seaweed were found in remains of dwellings at Monte Verde, Chile, dating from 14,220 to 13,980 years ago (Dillehay et al. 2008).

One wild plant that we surmise provided significant sustenance was the lotus, although it has not entered the archaeological record. Its root is still consumed in 'large quantities' throughout eastern Asia. Yet, we lack concrete ethnographic production and consumption figures, but we are in the process of gathering data on lotus consumption.

While we cannot present concrete data on whale beachings, they do exist in eastern China (but somehow not listed on Wikipedia's list of beached whales). The following link, not only shows the immense size of whales, but also the utilization of whale meat by Chinese locals: https://www. chinasmack.com/meat-of-dead-beached-whales-cut-off-overnight.

Might the early Chinese have hunted whale like the Tlingit did (cf. Bancroft 1875: 103)? We cannot say. But for sure, they would have butchered them on the beach with nothing surviving for archaeologists to find. One very important focus of future archaeology will be how to make interpretations with a lack of demonstrable data.

\section{AGRICULTURE}

Dickson (1987) attempted to add to Carneiro's theory by documenting a circumscription by anthropogenic environmental destruction in southern Mesopotamia. He notes that Carneiro distinguishes two contrasting ecologies: the circumscribed and the extensive, and he quotes: '...The Amazon basin or eastern woodlands of North America, where extensive and unbroken forests that provided almost unlimited agricultural land' (Carneiro 1970: 734-735).

There are two problems with this thinking. First, as we have noted, early states were still in the process of domesticating plants critical for agriculture; so to note that the eastern woodlands did not derive states via agriculture has the cart before the horse. And it is here that we again fortify our theory of early state formation. All early states appeared in areas 
with a concentrated abundance of wild resources, both plant and animal. Neither the Amazon basin nor the U.S. eastern woodlands had that.

Second, full utilization of 'unlimited' agricultural land of the eastern woodlands with heavy forestation eventually required a steel-based technology; not known there prior to European contact. Also, regarding the eastern woodlands, none of the early states were in areas of heavy snow. We also point out, that not just any area where a river meets a sea will produce a state, not even a village. It requires one with abundant concentrated wild-food resources. Of course, this is why states did not arise in the Amazon, or support one later. (And obviously, not everywhere that whales beached with regularity did a state arise [cf. Santos et al. 2015].)

Wild food resources are not sufficient to support any state level population, thus all required some form of incipient, if not 'advanced', agriculture. All early states worldwide were in a continuum of domestication of specific subsistence plants in their regions, thus eventually breaking the need for heavy reliance on wild resources (see Dillehay, Eling, and Rossen 2005). Once this happened, the location of major centers shifted to areas of higher agricultural productivity.

Arnold (2009) notes that the Olmec, with agrarian adjustments (increased maize production) $c a$. $900 \mathrm{BC}$, moved out of the floodplains into upland areas. Also, some of the later major urban sites were also in more central geographic areas, such as Teotihuacan in the Basin of Mexico. As for the latter, we are not saying that people necessarily migrated from the areas of early states to create later more complex states; rather, state centers probably shifted for a host of factors, such as centralized trade, and more than likely a shift in ethnicity occurred.

To understand this shift in state centers, we need to realize that cognitive decisions are fundamental for our understanding of how subsistence practices were viewed in the future tense by members of early states. There was a dynamic of plant domestication, that had begun earlier than any of the early states. As Piperno (2011) states in her excellent analysis of plant cultivation and domestication in the New World tropics: the emphasis on a flexible phenotype means that HBE's (human behavior ecology) engine for change resides in human decision-making.

Again, in Mexico the major state center shifted away from the gulf coast to central Mexico with Teotihuacan becoming the largest site in Mesoamerica. Still, the roots of the earliest state, the Olmec, are in some form manifested in the reconfigurations of all later Mesoamerican states (cf. Stocker and Ortega N.d.; Killion and Urcid 2001), and such ideological heritage (from early states to later ones) surely applies around the world (cf. Janusek 2016).

In China the state center would move from Liangzhu to the Louyang center in Hunan Province to Xi'an in Shaanxi Province. Xi'an, a walled city engaged in 'constant' warfare; being the home of 13 different ethnic 
dynasties before the capital was moved to Beijing for defensive purposes against groups in upper northeast China. The beauty of the Chinese case is that once the Western Zhou established the capital in Xi'an (1050 BC to $478 \mathrm{BC}$ ), we have written records with incessant warfare being the most central feature.

Parenthetically, it is because we worked in these areas that we are able to contribute to the matter of state formation ( $c f$. Stocker and Spence 1973; Xiao and Stocker N.d.). We note: a critical issue for anyone from the West writing about China's archaeology is that very little has been translated into English. Xiao has written some 100 tomb-excavation summaries for his government; none have been translated into English.

Returning to the eastern woodlands of the U.S., once agriculture did become nearly fully developed in North America, the immense site of Cahokia arose at the confluence of the Missouri and Mississippi Rivers. It is beyond the boundaries of this paper, but: Was Cahokia a state? Some scholars contend this ( $c f$. Holt 2009) and we will add: Monks Mound is larger than any structure of the Aztec Empire. (Likewise, the Hopewell culture of Ohio was located along rivers (see Mueller 2018; Horton and Stocker 2019).

While agriculture developed, increasing human populations impacted the animal populations they relied upon in one manner or other. In some cases this led to vital animal husbandry (see Manin et al. 2018); in other cases, this led to the decimation of critical wild animal populations. For example, in Babylonia the lust for crocodile pelts led to the extinction of the Euphrates crocodile (Stocker, Meltzoff, and Armsey 1980). As for Mesoamerica, we are in need of figures on deer populations, which were hunted to virtual extinction after Spanish contact.

\section{SOCIAL/IDEOLOGICAL FACTORS}

Some scholars believe that ideas/ideology are the prime movers giving rise to the state. Claessen (2004: 79) informs us that a state cannot come into being without an ideology explaining and justifying a hierarchical administrative organization and socio-political inequality (see also Claessen 2000, 2010). In other words, ideology makes the non-elite not only accept their working/living conditions but also makes them accept the advantages and control of the elite. We agree with this, but such an ideology existed before the state and co-existed with states in non-state societies (see Idem 2016).

The degree to which ideology enters early state formation, does not impact Unique Resource Constellation Theory. If a location does not have enough resources to support a large population, the state level of social organization cannot be achieved, no matter what the ideology.

We understand that we cannot just use ecology to 'understand' early states ( $c f$. Murphy 2016), and ideology is a factor (cf. Trigger 1993). As 
noted earlier, slavery surely was a mechanism of social control for many early states, like Egypt. The main hallmark of early states, monumental architecture also often required slave labor. In Mexico, with its heart sacrifice, out groups had to be constantly raided. Human sacrifice existed before Mexico's earliest states, but we know the Olmec conducted heart sacrifice, which possibly figured in their demise.

All states, early or late, have the one commonality of a religion that was created and utilized to impose control through a belief system that benefited the elite. Stocker and Ortega (N.d,) have argued for a cognitive approach to understanding material culture. The leaders of early states created religions complete with ceremonies requiring participation of the masses. Through time, many of the main centers became pilgrimage centers (worldwide), providing ceremonial diversion for a population that daily practiced the drudgery of subsistence agriculture.

Of course, religion does not explain why any people originally populated specifics areas; but once they were there, they began creating large buildings and sculptures. San Lorenzo has so far produced 10 of the 17 large Olmec basalt heads (one weighing 28 metric tons and 3 meters high), and hundreds of religious artifacts (Pool 2007). Those heads were not created to invoke spirits to help with subsistence practices - at least directly, but are a testament to the role of conquest warfare in early states. Obviously, states are not one site in isolation; so, we assume that the movement of those heads from the quarry some 150 kilometers away required not just the population of San Lorenzo but many of the surrounding sites.

States or non-states, certain segments of the elite would create religions and the elements of some of those religions would last until the present day. This is certainly true in Mesoamerica, and as Stocker and Ortega (N.d.) proposed in their cognitive approach to Olmec religion: to reconstruct the past, artifacts and art motifs cannot be separated from the minds that created them, and those minds cannot be alienated from the environment(s) in which they existed. They proposed that somewhere in Mesoamerica, where crocodiles lived, the Cult of the Crocodile began, as symbolism of the elite (in a constellation of other animals and plants) and spread across the landscape, complete with pilgrimages that were extant at Spanish contact. Crocodilian imagery, of Olmec ancestry, exists in many Mexican colonial churches (Stocker and Jackson 1983).

Spanish conquerors quickly replaced many Native American pilgrimage deities with Catholic saints; and to this day, pilgrimage is a fundamental aspect of Mexican Catholicism. Stocker (a non-Christian) has made the three-day walking pilgrimage, beginning in Tula, Hidalgo, outside the Basin of Mexico, to what was the Aztec mother goddesses' shrine (now the Basilica of the Virgin of Guadalupe, the most visited site in the Catholic realm). To accomplish this, Stocker (along with all the other 
pilgrims) with no great exertion walked over the mountains of the Basin of Mexico, which Carneiro proposed would hem in people.

Pilgrims obviously walked, and walk, over the lowest passes in the mountains. However, many rituals were conducted on the highest peaks throughout Mesoamerica ( $c f$. Milbrath 2017; Broda 2016), and such peaks even challenge anthropological mountain climbers, like Stocker. It is imperative that anyone interested in this topic see the photograph of the procession on the glacier of Qullqipunku during Qoyllur Rit'i in John Wayne Janusek's (2016) 'Processions, Ritual Movements, and the Ongoing Production of Pre-Columbian Societies, with a Perspective from Tiwanaku.' That stunning photo alone is proof that mountains hemmed in no one (and kept no one out). And for a final mention on the topic, we recommend Palladino's (2017) comments on transhumance.

Certain cognitive/ideological decisions of the religious elite impacted archaeological remains. For example, we know from ethnographic documentation that Native Americans ate bear and that after butchering a bear, a holy animal, the bones were to be disposed of by throwing them in a river or placing them in trees, so that dogs would not eat them and desecrate the holy animal (Hallowell 1926). Stocker, Meltzoff, and Armsey (1980) suggested this possible practice for the Olmec and crocodilians. Skewed archaeological remains will haunt archaeologist until the end (cf. Smith and Kinahan 1995).

In the context of the foregone, for us, our critique and hopeful dismissal of Carneiro's theory is secondary. Primarily, we hope to instill urgency for anthropologists and archaeologists to document and quantify. For example, Frieberg (1954: 191) wrote of certain South American groups hunting crocodilians with axes and clubs, but we know nothing of quantity or butchering techniques (including disposal of bones) or cooking techniques or consumption. Archaeologists need anthropologists more than ever; and with globalization, the hour is getting late (Stocker N.d.). Indeed, the journal Ethnoarchaeology first appeared less than a decade ago, in 2009.

Finally, as states grew in population, many, if not all, made the assessment to conquered smaller populations, eventually leading to small empires (see Abramson 2017; Carneiro 1978). Obviously, state conquests created enemies, and those enemies might figure into the abandonment of the early state centers and movement to other areas.

\section{CONCLUSION}

We are forced to divide our conclusions into two parts: one dealing with Carneiro, the other being Unique Resource Constellation Theory.

Certain individuals noted that our critique of Carneiro 1970 might be overly harsh, seeing that it was nearly 50 years ago. We invite anyone to read Carneiro 2012a. Does Carneiro's (1970: 736) characterization 
sound scientific: ...often new facts are stubborn and do not conform to the theory...? This writing (thinking) style continues in Carneiro 2012a.

Carneiro (2012a: 10-11) informs us of the abundant number of textbooks promoting circumscription theory, and he quotes Harris

There is a very good fit between this model of pristine state formation and the conditions that existed in the regions most likely on archaeological evidence to have been the centers of formation of pristine states. Egypt, Mesopotamia, northern India, the Yellow River Basin, central highland Mexico ... and the Peruvian coastal rivers and Andean highlands are all sharply [environmentally] circumscribed...(Harris 1979: 102).

For sure, the impacts of these basic textbooks still hold sway, as we have learned from trying to discuss early state formation with many people. Carniero then writes:

To be sure, slight modifications might have to be made in the basic theory in order to take account of peculiar features in the rise of certain states. But nothing more than this should be required. To give an analogy, the minor modifications that might have to be made in the general theory could be likened to altering the distributor cap in an automobile engine, adjusting the flow of current to the various spark plugs, but maintain the functions of the engine essentially unchanged (Carneiro 2012a: 12).

On the same page of this analogy, he promotes the Maya as possible contenders of 'full-blown' archaic state, again without mentioning any site or reference. This is not a good scholarship as well; we completely disagree. For us, his engine is broken.

And we are also informed:

The first interpretation of multicausality... holds that in every case of state formation a different set of factors was at work. Each state that arose - in Egypt, in China, in the Andes, or anywhere - had its own unique set of determinants. No single theory could hope to account for more than one or two instances of it (Carneiro 2012a: 6-7).

We fundamentally disagree and maintain that all early states arose in the locations where they did because sufficient wild food resources could support a large aggregate of people. We label this Unique Resource Constellation Theory.

Regardless of the future of our contribution to understanding of early states, we are adamant that there are no physical circumscriptions (or social) to confine populations in the areas of early states. We return to Carneiro's (2012a: 12) statement: '...we are forced to conclude that tight geographic constrictions, while greatly aiding state formation is not absolutely essential to it.'

Surely, with Zinkina, Korotayev, and Andreev's (2016) critique of the warfare aspect of circumscription theory and our critique of the ecological 
aspects, we can dispense with circumscription theory. Hopefully, if anyone desires to continue it in the future, data will be presented in a scholarly fashion.

The entire issue of Social Evolution \& History, Volume 11 (2) 2012 dealt with the origin of the early state, 22 articles, with the main thrust being to evaluate 'circumscription theory.' Carneiro (2012b) wrote a lengthy 59-page response. Of course, we cannot entertain the entire gamut of issues raised, from those wanting a greater consideration of ideology to those wanting a more 'refined' definition of the state.

Many argue that warfare often occurs as a type of competitive interaction in the absence of population pressure. Carneiro (Ibid.: 135) accepts this fact and writes, 'Some critics might be quick to affirm that this admission represents a serious challenge to the circumscription theory ... I think not ... What it does - as I suggested in my "Reformulation" [Carneiro 2012a] - is to raise the question of whether the circumscription theory might better be called by a different name.'

He offers no other name, and we would simply say: A rose by any other name...

He ends on this note:

Now, what lies ahead in our study of the rise of chiefdoms and states? ... For me, the most rewarding avenue is clear: theorists should declare a moratorium on reading each other's conjectures and turn instead to a consideration of the facts. Solid evidence is the bedrock on which successful theories are built (Idem 2012b: 186).

Facts are what we have presented in this article. The two main ones are: One, mountains do not circumscribe any population. Two, no statesize population can exist without a food base to feed said population. It is for this reason that the archaic/pristine states only arose in a few places on planet Earth.

Unique Resource Constellation Theory will need future attention to demonstrate more fully that the locations of early states were on or near certain rivers locations with abundant renewable fish populations as the main variable in an assemblage of other wild animal and plant resources. These resources were essential, to support a large population, in tandem with agricultural efforts, varying in degree from one area to another. (And we might assume that those rivers were vital for agricultural irrigation.)

As any population, state or otherwise, outran resources, out-migration was necessary for certain segments of that population, a prime example being the Norse establishment (and abandonment) of colonies on Greenland ( $c f$. Zorich 2017). Obviously, the Norse were not one of the pristine states, but we use them for two reasons. The first one, Carneiro sees bodies of water as impediments to early human movement (escape). We are not convinced of this, but it is a matter for another time. Second, paradigm shift, as nearly every anthropologist knows, can be slow; and like the idea of a Norse exploration of North America finally being ac- 
cepted (Irwin 1980), we assume it will be some time before Unique Resource Constellation Theory is accepted. Of course, more data should be mustered for its acceptance.

It is a fact that many early migrants to the Americas came for subsistence reasons, even though the initial cause of colonization was empire conquest/expansion (even if couched as spice trade). A decline in food resources would make any early state center vulnerable to possible outside aggression, which might explain abandonment of certain early state centers.

Finally, as we wrote previously, once agriculture became developed state centers shifted away from the locations of pristine states. As agriculture, along with trade, became more sophisticated the great urban centers of academic achievement would eventually arise: New York, London, Moscow; and the locations of pristine states became isolated areas of archaeological interest. Anyone has to ask him or herself: Why were the centers of pristine states located where they were, and not in New York or Los Angeles or Canada or Kazakhstan or Uruguay or Tanzania or Germany? The answer is simple: those places did not have any locations of Unique Resource Constellation.

We base our conclusions, in part, on studies of, and first-hand experiences of, food procurement. We hope that the readers of this article will at least look at the last photo in Stocker 2015 - immediately accessible at any search engine. We have been in the process, for years, of studying wild food resources in China and hope to publish our findings soon.

\section{ACKNOWLEDGEMENTS}

We greatly profited from assiduous critiques by Alice Kehoe, Guy Hepp, and Roz Frank. A very special thanks to Mark Munn. Also, Susan Milbrath, Jack Lamb, Paul Roscoe, Richard Gallerno, and William Ayres provided meaningful commentary. Anonymous reviewers of our manuscript provided vital direction in making this a more definitive article.

\section{REFERENCES}

Abramson, S. 2017. The Economic Origins of the Territorial State. International Organization 71 (1): 97-130.

Aldred, C. 1987. The Egyptians. London: Thames and Hudson.

Arnold III, P. 2009. Settlement and Subsistence among the Early Formative Gulf Olmec. Journal of Anthropological Archaeology 28: 397-411.

Bancroft, H. 1875. The Native Races of the Pacific States of North America. London: Longmans, Green, and Co.

Bost, J. 2009. Edible Plants of the Chinantla, Oaxaca, Mexico with an Emphasis on the Participatory Domestication Prospects of Persea Schiedeana. Master Thesis. Gainesville, Florida: University of Florida.

Broda, J. 2016. Processions and Aztec State Rituals in the Landscape of the Valley of Mexico. In Evans, S. (ed.), Processions in the Ancient Americas. Occa- 
sional Papers in Anthropology 33: 179-205. Department of Anthropology, Pennsylvania State University.

Bruhns, K. 1994. Ancient South America. Cambridge; New York: Cambridge University Press.

Bye Jr., R. A. 2000. Quelites - Ethnoecology of Edible Greens - Past, Present and Future. In Minnis, P (ed.), Ethnobotany (pp. 197-213). Norman, OK: University of Oklahoma Press.

Caballero, J. Casas, A., Cortes, L., and Mapes, C. 1998. Patrones en el conocimiento, uso y manejo de plantas en pueblos indígenas de México. Revista de Estudios Atacameños 16: 181-196.

Carneiro, R. 1970. A Theory of the Origin of the State. Science 169: 733-773.

Carneiro, R. 1972. From Autonomous Villages to the State, a Numerical Estimation. In Spooner, B. (ed.), Population Growth: Anthropological Implications (pp. 64-72). Cambridge, MA: MIT Press.

Carneiro, R. 1978. Political Expansion as an Expression of the Principle of Competitive Exclusion. In Cohen, R., and Service, E. R. (eds.), Origins of the State (pp. 205-223). Philadelphia, PA: Institute for the Study of Human Issues.

Carneiro, R. 1987. Further Reflections on Resource Concentration and its Role in the Rise of the State. In Manzanilla, L. (ed.), Studies in the Neolithic and Urban Revolutions (pp. 245-260). British Archaeological Series 349.

Carneiro, R. 1988. The Circumscription Theory: Challenge and Response. American Behavioral Scientist 31: 497-511.

Carneiro, R. 1998. What Happened at the Flashpoint? Conjectures on Chiefdom Formation at the very Moment of Conception. In Redmond, E. (ed.), Chiefdoms and Chieftaincy in the Americas (pp.18-42). Gainesville, FL: University Press of Florida.

Carneiro, R. 2000. The Muse of History and the Science of Culture. New York, NY: Kluwer Academic/Plenum Publishers.

Carneiro, R. 2004. Was the Chiefdom a Congelation of Ideas? In Grinin, L. et al. (eds.), The Early States: Its Alternatives and Analogues (pp. 28-45). Volgograd: 'Uchitel' Publishing House.

Carneiro, R. 2012a. The Circumscription Theory: A Clarification, Amplification and Reformulation. Social Evolution \& History 11: 5-31.

Carneiro, R. 2012b. Answer to Critiques. Social Evolution \& History 11: 131-190.

Carneiro, R. 2016. The Chiefdom in Evolutionary Perspective. In Carneiro, R., Grinin, L., and Korotayev, A. (eds.), Chiefdoms Yesterday and Today (pp. 15-59). Clinton Corners, NY: Eliot Werner Publications.

Casas, A., Otero-Arnaiz, A., and Perez-Negron, E. 2007. In situ Management and Domestication of Plants in Mesoamerica. Annals of Botany 100: 1101-1115.

Casas, A., Viveros, J. L., Katz, E., and Caballero, J. 1987. Las plantas en la alimentación mixteca: una aproximación etnobotánica. América Indígena 47: 317343.

Chi, Zhang, and Hsiao-Chun Hung, 2008. The Neolithic of Southern China Origin, Development and Dispersal. Asian Perspectives 47: 299-329. 
Claessen, H. J. M. 2000. Structural Change; Evolution and Evolutionism in Cultural Anthropology. Leyden: CNWS.

Claessen, H. J. M. 2004 Was the State Inevitable. In Grinin, L. et al. (eds.), The Early States: Its Alternatives and Analogues (pp. 72-87). Volgograd: 'Uchitel' Publishing House.

Claessen, H. J. M. 2010. On Early States - Structure, Development, and Fall. Social Evolution \& History 9 (1): 3-51.

Claessen, H. J. M. 2016. On Chiefs and Chiefdoms. In Carneiro, R., Grinin, L., and Korotayev, A. (eds.), Chiefdoms Yesterday and Today (pp. 109-128). Clinton Corners, NY: Eliot Werner Publications.

Clark, J., and Pye, M. 2000. The Pacific Coast and the Olmec Question. In Clark, J., and Pye, M. (eds.), Olmec Art and Archaeology in Mesoamerica (pp. 216251). Washington, D.C.: National Gallery of Art.

Clement, Ch. et al. 2015. The Domestication of Amazonia Before European Conquest. Proceedings of the Royal Society B. 282 (1812).

Denevan, W. 2001. Cultivated Landscapes of Native Amazonia and the Andes. Oxford: Oxford University Press.

Dickson, D., and Bruce 1987. Circumscription by Anthropogenic Environmental Destruction: An Expansion of Carneiro's (1970) Theory of the Origin of the State. American Antiquity 52 (4): 709-716.

Dillehay, T., Ramirez, C., Pino, M., Collins, M. B., Rossen, J., and Pino-Navarro, J. D. 2008. Monte Verde: Seaweed, Food, Medicine, and the Peopling of South America. Science 320: 784-786.

Dillehay, T., Eling, H. Jr., and Rossen J. 2005. Preceramic Irrigation Canals in the Peruvian Andes. Proc Natl Acad Sci 102 (47): 17241-17244. Doi: 10.1073 / pnas.0508583102.

Frieberg, M. 1954. Vida de batrachios y reptiles Sudamericanos. Buenos Aires: Cesarini.

Grinin, L. 2004. The Early State and Its Analogues: A Comparative Analysis. In Grinin, L. et al. (eds.), The Early States: Its Alternatives and Analogues (pp. 88-136). Volgograd: 'Uchitel' Publishing House.

Haas, J. 1982. The Evolution of the Prehistoric State. New York: Columbia University Press.

Hallowell, A. 1926. Irving, Bear Ceremonialism in the Northern Hemisphere. American Anthropologist 28: 1-161.

Harris, M. 1979. Cultural Materialism: The Struggle for a Science of Culture. New York: Random House.

Hecht, S., and Cockburn, A. 2011. The Fate of the Forest: Developers, Destroyers, and Defenders of the Amazon. Chicago, Ill.: University of Chicago Press.

Heckenberger, M. et al. 2003. Amazonia 1492: Pristine Forest or Cultural Parkland? Science 301: 1710-1714.

Holt, J. Z. 2009. Rethinking the Ramey State. Was Cahokia the Center of a Theater State? American Antiquity 47: 231-254. 
Horton, G., and Stocker, T. 2019. The Woman Who Fell from the Sky and The Portsmouth, Ohio Hopewell Earthworks. Journal of Ohio Archaeology 6: $1-15$.

Irwin, C. 1980. Strange Footprints on the Land. New York: Harper \& Row.

Janusek, J. W. 2016. Processions, Ritual Movements, and the Ongoing Production of Pre-Columbian Societies, with a Perspective from Tiwanaku. In Evans, S. (ed.), Processions in the Ancient Americas. Occasional Papers in Anthropology 33: 1-26. Department of Anthropology, Penn State University.

Killion, T. 2013. Nonagricultural Cultivation and Social Complexity. The Olmec, Their Ancestors, and Mexico's Southern Gulf Lowlands. Current Anthropology 54: 569-606.

Killion, T., and Urcid, J. 2001. The Olmec Legacy: Cultural Continuity and Change in Mexico's Southern Gulf Coast Lowlands. Journal of Field Archaeology 27 (1/2): 3-25.

Lanning, E. 1967. Peru before the Incas. Englewood Cliffs, N.J.: Prentice-Hall.

Lin, Chao-Qi et al. 1973. Fuguodun shell midden in Jinmen. Bulletin of the Department of Anthropology 33/34: 36-38. Taipei: Department of Archaeology and Anthropology, National Taiwan University, Taipei (in Chinese).

Lira, R., Casas A., and Blancas, J. 2016. Ethnobotany of Mexico. New York: Springer.

Liu, Bin, and Qin, Ling (eds.) 2018. Liangzhu Culture: Society, Belief, and Art in Neolithic China. Routledge.

Manin, A. et al. 2018. Diversity of Management Strategies in Mesoamerican Turkeys: Archaeological, Isotopic and Genetic Evidence. Royal Society Open Science. DOI.org/10.1098/rsos.171613.

Milbrath, S. 2017. Seasonal Images in the Art of Central Mexico. In Finegold, A., and Hoobler, E. (eds.), Visual Culture of the Ancient Americas: Contemporary (pp. 163-168). Norman: University of Oklahoma Press.

Morell-Hart, Sh., Joyce, R. A., and Henderson, J. S. 2014. Multi-Proxy Analysis of Plant Use at Formative Period Los Naranjos, Honduras. Latin American Antiquity 25: 65-81.

Morton, J. and Dowling, C. F. 2013. Fruits of Warm Climates. Brattleboro, VT: Echo Point Books and Media.

Mueller, N. 2018. The Earliest Occurrence of a Newly Described Domesticate in Eastern North America: Adena/Hopewell Communities and Agricultural Innovation. The Journal of Anthropological Archaeology 49: 39-50.

Murphy, J. 2016. Ritual and Archaic States. Gainesville: University Press of Florida.

Palladino, P. 2017. Transhumance Revisited: On Mobility and Process Between Ethnography and History. Journal of Historical Sociology 31: 119-133. DOI: 10.1111/johs. 12161 .

Piperno, D. 2011. The Origins of Plant Cultivation and Domestication in the New World Tropics: Patterns, Process and New Developments. Current Anthropology 52: 453-470. 
Plummer, K. 1984. The Shōgun's Reluctant Ambassadors. Oregon Historical Society.

Pool, C. 2006. Una Vista Desde el Oeste: Tres Zapotes y el Paisaje Politico Olmeca. Paper presented at the $52^{\text {nd }}$ International Congress of Americanists. Seville, Spain.

Pool, C. 2007. Olmec Archaeology and Early Mesoamerica. Cambridge: Cambridge University Press.

Quilter, J. et al. 1991. Subsistence Economy of El Paraíso, an Early Peruvian Site Science 250: 277-283.

Quilter, J., and Stocker, T. 1983. Further Considerations of the Maritime Foundations of Andean Civilization. American Anthropologist 85: 545-562.

Quilter, J. 1985. Architecture and Chronology at E1 Paraíso, Peru. Journal of Field Archaeology 12: 279-207.

Sanderson, S. K. 1990. Social Evolutionism. A Critical History. Oxford: Basil Blackwell.

Santley, R. 2007. The Prehistory of the Tuxtlas. Albuquerque: University of New Mexico Press.

Santos, J. I. et al. 2015. Effect of Resource Spatial Correlation and Hunter-Fisher Gather Mobility on Social Cooperation in Tierra del Fuego. PLoS ONE 10 (4): e0121888.

Schaedel, R., and Robinson, D. 2004. The Pristine Myth of the Pristine State. In Grinin, L. E. et al. (eds.), The Early States: Its Alternatives and Analogues (pp. 262-277). Volgograd: 'Uchitel' Publishing House.

Service, E. 1975. Origins of the State and Civilization. New York: W. W. Norton.

Silverstein, J. 2001. Aztec Imperialism at Oztuma, Guerrero. Ancient Mesoamerica 12: 31-48.

Smith, A., and Kinahan, J. 1984. The Invisible Whale. World Archaeology 16: 91-97.

Stocker, T. 1986. Wild Growing Plant Utilization by the Otomi Indians. Mexicon 8: 69-72.

Stocker, T. 1987. Conquest, Tribute and the Rise of the State. In Manzanilla, L. (ed.), Studies in the Neolithic and Urban Revolutions (pp. 365-376). British Archaeological Series 349.

Stocker, T. 2002. It Happened So Fast! Changing Korea, Critical Years 19941997. ROK, Heliot House.

Stocker, T. 2015. Aspects of Market and Culinary Variation. Globalethnographic.com.

Stocker, T. N.d. What's in a Name? Manuscript to be submitted to Globalethnographic.com.

Stocker, T., and Jackson, B. 1982. Peru's Preceramic Menu. Field Museum of Natural History Bulletin 53: 12-23.

Stocker, T., and Jackson, B. 1983. Precolumbian Style Murals in a Mexican Church. Field Museum of Natural History Bulletin 54 (2): 14-21. 
190 Social Evolution \& History / September 2019

Stocker, T., and Kylar, E. 1984. Aztec Warfare and Annihilation. Explorers Journal 61: 81-122.

Stocker, T., Meltzoff, S., and Armsey, S. 1980. Crocodilians and Olmecs: Further Interpretations in Formative Period Iconography. American Antiquity 45: 740-758.

Stocker, T., and Ortega, V. N.d. El Culto del Cocodrilo: Cognición para el Arte Mesoamericano Formativo Temprano. Arqueologia. In Press.

Stocker, T., and Spence, M. 1973. Trilobal Eccentrics at Teotihuacan and Tula. American Antiquity 38: 195-199.

Trigger, B. 1993. The State-Church Reconsidered. In Henderson, J., and Netherly, P. (eds.), Configurations of Power (pp. 74-111). Ithaca: Cornell University Press.

Tseng, C. M. 1981. Phycoculture in China. Proceedings of the International Seaweed Symposium 10: 124-152.

Underhill, A. 2013. A Companion to Chinese Archaeology. Chichester: WileyBlackwell.

Vázquez-García, V. et al. 2004. Los quelites de Ixhuapan, Veracruz: disponibilidad, abastecimiento y consumo. Agrociencia 38 (4): 445-455.

Xiao, J., and Stocker, T. N.d. Buddhist Persecution in Ancient China. Paper in the authors' possession to be submitted for publication.

Ying, Z. 2007. The Dawn of the Oriental Civilization: Liangzhu Site and Liangzhu Culture. Beijing: China Intercontinental Press.

Zinkina, J., Korotayev, A., and Andreev, A. 2016. Circumscription Theory of the Origins of the State: A Cross-Cultural Re-Analysis. Cliodynamics: The Journal of Qualitative History and Cultural Evolution 7 (2): 187-203.

Zorich, Z. 2017. Greenland's Vanished Vikings. Scientific American 316 (6): 64-74. 